\title{
Cues to Care: Are city landowners willing to make ecological landscapes?'
}

\author{
Mark Hostetler ${ }^{2}$
}

The purpose of this publication is to inform homeowners, developers, environmental horticulture Extension agents, and city officials about potential considerations to make urban landscapes more eco-friendly and aesthetically pleasing. Regarding biodiversity conservation in urban areas, homeowners, developers, landscape architects, environmental horticulture Extension agents, planners, and other design professionals make decisions that impact how yards and urban common areas are designed and managed. With the goal of improving urban biodiversity, people are trying to bring more vegetative complexity and native plants into urban landscapes. Although not discussed here, it is important to design and manage urban areas for biodiversity. (See these resources: forest fragments, conservation developments, and planning tools). Currently, there are minimum landscaping recommendations that are based on aesthetics research from the landscape architecture field. However, as discussed below, this research is flawed. The focus here is to explore avenues to balance aesthetics with installation of more environmentally friendly landscapes that provide wildlife habitat and reduce natural resource consumption, which is called an ecological landscape (Hostetler 2020).

When talking about ecological landscapes, homeowners, design professionals, and other built environment professionals often say, "Well, it cannot be too messy!" An immediate thought is: What is "too messy?" Aesthetic preferences are in the eye of the beholder and are shaped by experiences, culture, societal norms, and values. A continuum exists between highly manicured landscapes that contain mainly mowed turfgrass and non-native plants to totally wild yards that contain mainly native plants (Figures 1-4). Some ecologists probably see the beauty of a wild, structurally diverse, native-plant yard. Nevertheless, one cannot ignore cultural and societal norms because an ecological landscape design may be rejected by some homeowners. Even politics matters, given that some city ordinances may prohibit more natural yards (e.g., everyone must have a mowed lawn). The best-intentioned ecologist may not get anything implemented because of these challenges.

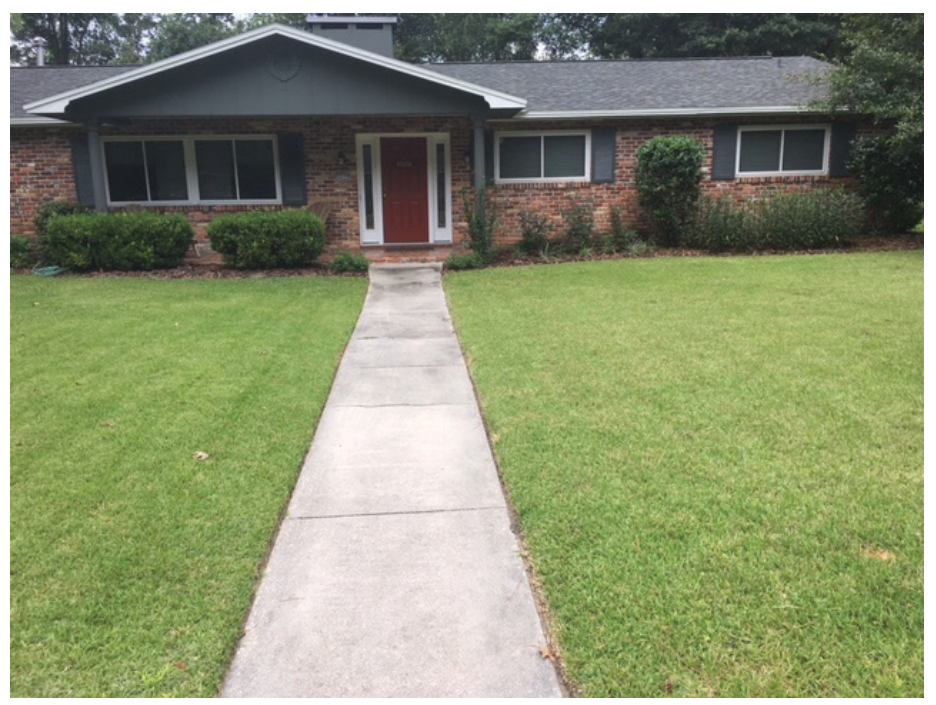

Figure 1. A conventional yard in Gainesville, Florida. It is dominated by lawn and ornamental bushes.

Credits: Mark Hostetler

1. This document is WEC-444, one of a series of the Wildlife Ecology and Conservation Department, UF/IFAS Extension. Original publication December 2021. Visit the EDIS website at https://edis.ifas.ufl.edu for the currently supported version of this publication.

2. Mark Hostetler, professor and Extension specialist, Department of Wildlife Ecology and Conservation; UF/IFAS Extension, Gainesville, FL 32611.

The Institute of Food and Agricultural Sciences (IFAS) is an Equal Opportunity Institution authorized to provide research, educational information and other services

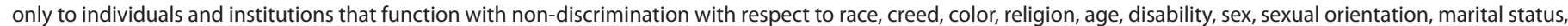

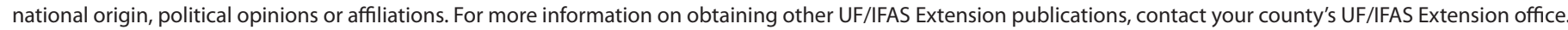
U.S. Department of Agriculture, UF/IFAS Extension Service, University of Florida, IFAS, Florida A \& M University Cooperative Extension Program, and Boards of County Commissioners Cooperating. Andra Johnson, dean for UF/IFAS Extension. 


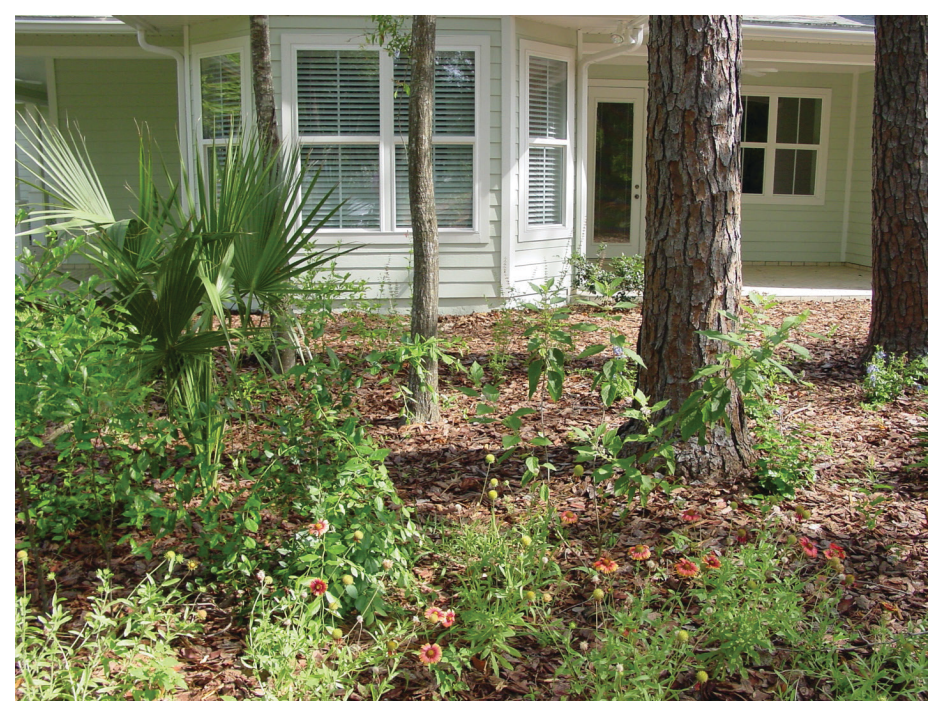

Figure 2. A relatively new Gainesville, Florida home with more natural landscaping. It has no lawn and does not require mowing. It conserved trees already present in the front yard and native plants were installed by a landscaper.

Credits: Mark Hostetler

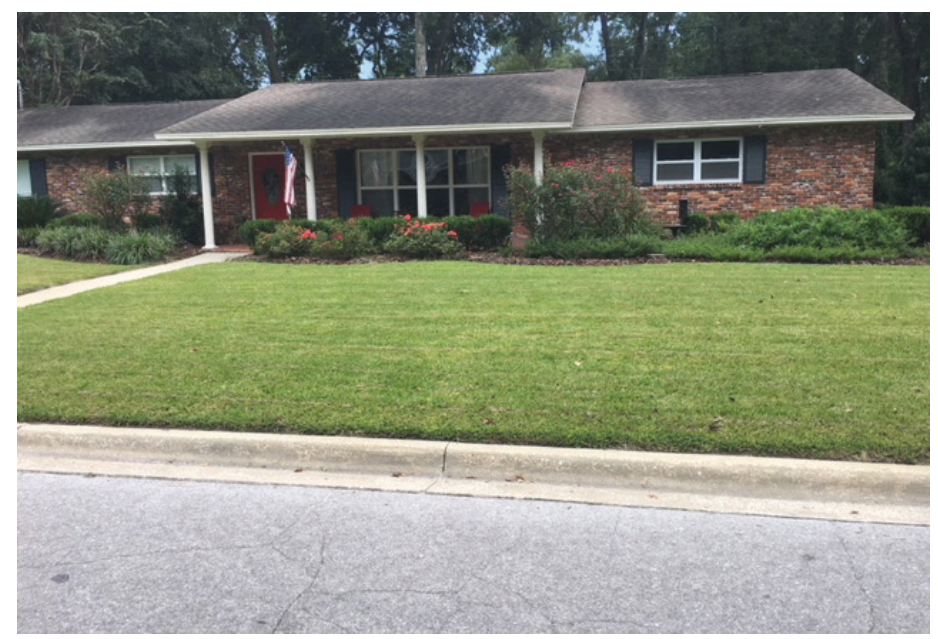

Figure 3. Another conventional yard in Gainesville, Florida. It is dominated by lawn and ornamental bushes.

Credits: Mark Hostetler

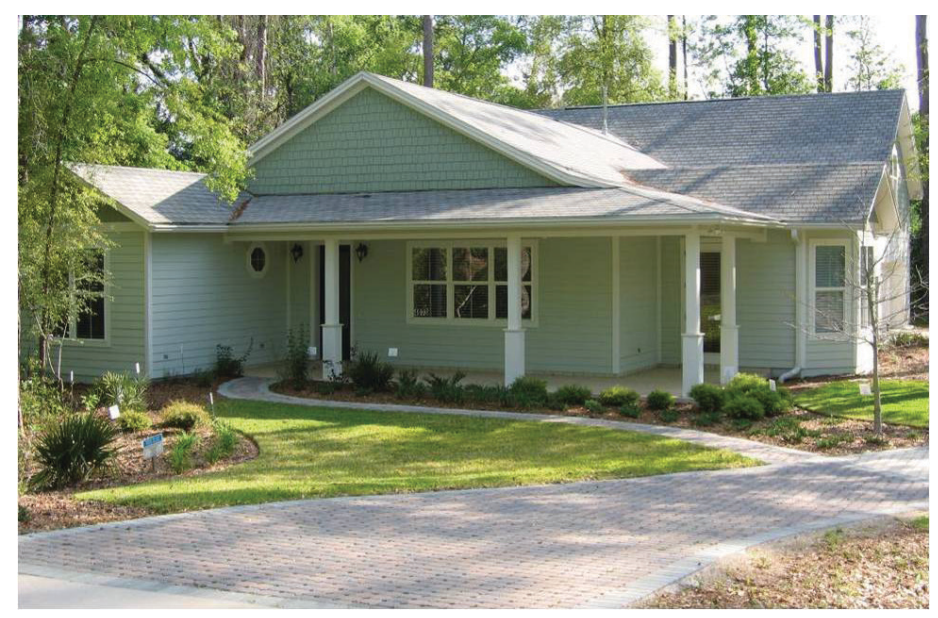

Figure 4. Another Gainesville, Florida home with more natural landscaping. It has a small patch of lawn, a natural landscaped rain garden, conserved trees, and a permeable paved driveway. Credits: Mark Hostetler
Enter cues to care theory. The term "cues to care" was coined by Joan Nassauer in a paper titled "Messy Ecosystems, Orderly Frames" (Nassauer 1995) and is a phrase used to describe actions undertaken by humans that indicate a landscape is well cared for and meets cultural expectations for maintenance. According to this theory, there is a common expectation in societies that landscapes will be looked after, managed, and maintained to acceptable standards. This assumption can be summed up, as Nassauer suggests, with the question "Does it look like they're taking care of it?" Cues to care theory is used in the context of creating ecological landscapes in cities. If we can figure out the minimum cues needed to make a landscape acceptable, we can incorporate more native structure into yards. But how many cues are needed? And what types of cues? For example, are one trimmed hedge and $20 \%$ mowed lawn the expected ingredients?

Past research has attempted to demonstrate the cues in a landscape design and how far front and back yards can be pushed down the ecological continuum before a homeowner revolts (Nassauer 1993) Overall there are very few studies on this topic, and most of these studies have not been conducted properly to determine which cues are needed and at what levels to help more eco-friendly yards to be accepted.

A review (Hostetler 2020) of previous studies (mainly conducted by Nassauer and others) indicated that they concentrated on a small subset of homes in a given city. In two representative studies by Nassauer (1993) and Visscher et al. (2012), Minneapolis-St. Paul and Detroit homeowners were surveyed to ascertain their landscaping preferences. Essentially, they were shown images of yards with varying degrees of vegetation structure, from mainly mowed to more "wild." They were then asked their preferences. The take-home message from these studies was that homeowners perceived the more native landscapes as messy and unattractive and more "cues to care" were required. In fact, in one study, Nassauer (1993) states that to garner homeowner acceptance, "As a general guideline, these mown areas should cover at least half the front yard."

Several problems are associated with the design and interpretation of these studies, which contain one or more of the following issues (for more details, see Hostetler 2020):

- First, the sample for one study was not random, which could create bias. People were invited to group events, and no effort was made to make the study a random sample. Thus, one cannot know if the surveyed group is a 
fair representation of all homeowners in that area of the city.

- Second, there was no attempt to address non-response bias. If the response to the survey was low (as it was in one study), what are the opinions of those that refused the survey? Again, one cannot know if the surveyed group fairly represented all homeowners in that area.

- Third, survey results only reflect the opinions of people in these particular neighborhoods in these particular cities. It cannot be extrapolated to represent an average across the United States, although such extrapolation is sometimes being done by design professionals (see below).

- Fourth, the sample of homeowners was drawn from neighborhoods with landscapes that had highly manicured lawns; therefore, the subjective norm was biased towards this particular type of landscape. Results would have been very different if, for example, homeowners were surveyed from neighborhoods that had very little lawn.

While the idea behind cues to care is laudable, we need to recognize, measure, and address aesthetic preferences properly if we are going to incorporate more native plants into yards. Overall, cues to care makes intuitive sense. We have all driven through or lived in neighborhoods, and our eyes make assessments of "messy" and "attractive" landscapes. Of course, the acceptability of a given landscape in a given city is dependent on each person's experiences, values, and subjective norms. One person's weed is another's wildflower.

The main point here is that we do not really know the level of cues that are needed when installing eco-friendly landscapes. Therefore, it is important to not apply the results that have been published to date. More research is needed to ascertain homeowner landscape expectations across different neighborhoods, cultures, and cities. For example, the acceptance would vary if respondents grew up near older residential yards with very few mowed lawns versus newer residential neighborhoods that have lots of lawn.

Of particular concern, we do not know how malleable these preferences are. For example, if homeowners were presented with the environmental and economic costs of a manicured yard versus an alternative yard, perhaps they would be more willing to adopt a more eco-friendly yard. If an entire neighborhood was designed from the beginning with very little turfgrass and had lots of native plants, would not the homeowners in these neighborhoods have a different acceptance level? A new subjective norm?
Take-home message? We cannot rely solely on research to date and must explore the boundaries of landscape preferences. Recommendations by decision makers should not refer to a "cue" that was a result of the aforementioned study, such as "As a general guideline, these mown areas should cover at least half the front yard."

Research should be conducted not only to determine how variable cues to care are from one context to the next, but to better understand how subjective norms could be changed by raising neighborhood awareness and creating working models of ecologically friendly yards. Such studies would result in more targeted solutions that would allow for higher levels of acceptance of-and even preference for-ecological design in yards.

Ultimately, the goal is to have both attractive and ecologically functioning human-dominated landscapes. Residential landscapes have typically been dominated by ornamental species and manicured lawns. The challenge of shifting landscape preferences remains, but the use of cues-to-care theory remains a potent and viable possibility for allowing more native plants and more "wildness" to be incorporated into yards. Because we do not know how much "cue" is needed to transition into a more eco-friendly landscape, one recommendation for decision makers is to discuss with the homeowner (or city planner, developer, and landowner) about their preferences to establish a natural landscape that works for them. Also, during this discussion, information about the benefits of a natural landscape could be taught because this has been shown to influence landowners to adopt more native landscaping (Peterson et al. 2012).

Imagine it in your mind's eye: A yard whose patches of natural landscaping feature complex vertical height vegetation bordered with landscaping rocks, trimmed hedges, etc. (i.e., cues to care). These bordering features would indicate human intent while simultaneously providing a more natural landscape in the yard itself. The Florida-Friendly Landscaping ${ }^{\text {TM }}$ Program from UF/IFAS Extension and the Florida Department of Environmental Protection has some literature and principles to help guide decision makers to transition to a yard that conserves natural resources and reduces the use of fertilizers and irrigation. (see https://ffl. ifas.ufl.edu/). Here are some top recommendations to create a more wildlife habitat in a yard (see more details Top Ten Tips, https://edis.ifas.ufl.edu/publication/uw175):

1. Limit the amount of lawn

2. Increase vertical layering 
3. Provide snags and brush piles

4. Provide water

5. Plant native vegetation

6. Provide bird/bat houses and bird feeders

7. Remove invasive exotic plants

8. Manage pets

9. Reduce pesticide use

10. Expand the scale of habitat

Perhaps even educational signage may be required to raise levels of awareness (see neighborhood signs). Researchers and practitioners alike need to explore peoples' preferences when incorporating more natural landscaping, and maverick planners/developers/homeowners need to try out new designs. Such studies and local examples will lead to the reduction of environmental impacts and create landscapes that are better for wildlife and humankind alike.

\section{References and Resources}

Hostetler, M. E. 2020. "Cues to Care: Future Directions for Ecological Landscapes.” Urban Ecosystems. https://doi. org/10.1007/s11252-020-00990-8

Hostetler, M. E., G. Klowden, S. W. Miller, and K. N. Youngentob. 2003. "Landscaping Backyards for Wildlife: Top Ten Tips for Success." Circular 1429/UW175. EDIS 2003 (1) https://doi.org/10.32473/edis-uw175-2003.

Nassauer, J. I. 1995. "Messy Ecosystems, Orderly Frames." Landscape Journal 14 (2): 161-170.

Nassauer, J. I. 1993. "Ecological Function and the Perception of Suburban Residential Landscapes" in P. H. Gobster, (ed.), Managing Urban and High Use Recreation Settings, General Technical Report (St. Paul, MN: USDA Forest Service North Central Forest Exp. Station.

Visscher, R. S., J. I. Nassauer, and L. L Marshall. 2012. "Homeowner Preferences for Wooded Front Yards and Backyards: Implications for Carbon Storage" Landscape and Urban Planning 146:1-10.

UF/IFAS Extension's Florida-Friendly Landscaping ${ }^{\mathrm{TM}}$

Program https://ffl.ifas.ufl.edu/ 